aneurysm of the arch. He thought that the ultimate solidification of the aneurysm, though its only method of cure, accounted for the sudden deaths which occasionally occurred some months later, owing partly to pressure effects and partly to the induction of syncope.

\section{Chronic Edema.}

At the Medical Society of London, Dr. Essex Wynter showed two cases of this comparatively unrecognized condition. A single woman, aged 23 , enjoyed good health till November, 1900, when she developed a cough which lasted through the winter. For the past ten years she had complained of attacks of misty vision lasting one or two minutes, which had lately increased in frequency. Three years ago there was some swelling of the lips and tongue noticed, chiefly on rising, and lasting two months. Swelling of the face and legs came on gradually and was notably worse since May, 1901, especially after walking or long standin's, the legs being at times so stiff she could only flex them with difficulty. In the mornings the swelling was softer and less distinct. The swelling of the face was noticed a few months earlier than in the legs, especially about the right eye. The general health appeared to be unaflected and there had been no pain. The thoracic and abdominal organs appeared to be normal. The urine contained no albumin. Temporary improvement in the swelling of the face and legs occurred under massage. Thyreid extract was given without effect. The second case was a girl. aged 17. About three months ago the face and hands were noticed to be swollen on rising and enlargement of the legs increased. The swelling increased daily and became more persistent. Recently she had noticed some dyspnea on exertion and polyuria. The face was pale and uniformly swollen, the eyes being half closed; the hands also werc swollen, but not distorted; and dimples over the knuckles were well marked. The legs were uniformly enlarged and very firm. only pitting slightly on sustained pressure, the skin not being white or shiny. The thoracic and abdominal organs appeared to be normal. The urine was pale, clear, alkaline, of $1009 \mathrm{sp}$. gr., and free from albumin. While lying in bed there was a marked improvement, but on the patient getting about the measurements of the body returned nearly to their original dimensions, but were not so hard.

\section{PARIS LETTER.}

Operation on the Hindoo Twins by Dr. Doyen.

An operation which has caused much comment in Paris is that which Dr. Doyen has just performed on the Hindoo twins of the Barnum and Bailey circus. Dr. Doyen, whose name is undoubtedly familiar to many American physicians. is the man who rushed across France to Rennes at the time of the Dreyfus affair to take an $x$-ray photograph of the bullet which had been fired at Labori and had lodged in his back. Professor Reclus was, however, the regular surgeon of the family and refused to have the bullet sought after or extracted. Dr. Doyen is now at loggerheads with another professor, this time the professor of infantile elinical surgery, Dr. Kirmisson. As the Hindoo twins were showing signs of failing health, they were taken to the new Trousseau Hospital, where they were found to be suffering with incipient consumption, and Doodica (the name of the other is Radica) presented symptoms of tubercular peritonitis. Professor Kirmisson was called into consultation by Dr. Guinon, but refused to operate unless he had a written authorization from the foster mother or the agent of Barnum and Bailey. The former would only give it on condition that she could assist at the operation and have it cinematographed. To this Dr. Kirmisson refused to consent, so the foster mother took the twins to Dr. Doyen's clinic, and the operation was carried out on February 9. The operation lasted in all only twenty minutes and Dr. Doyen has given the following account, which is printed in the Echo de Paris:

The two sisters were placed on a table covered with a sterilized cloth. I placed myself to the right and cut the skin above the connecting ligament. A certain -amount of cartilage was cut
through with a lancet. Two little veins alone had to be tied. The through with a lancet. Two little veins alone had to be tied. The
peritoneum was then cut and the hepatic band which always exists in such cases was laid bare. There were certain adherences on the side of Doodica, who, as the diagnosis had shown, was suffering from tubercular peritonitis. The hepatic bridge was 7 centimeters long and 4 centimeters in diameter. It seemed very vascular. This was a case for the employment of the method of hemostasis which I have invented. by the crushing of the hepatic pedicles with my double-lever forceps which gives instantly, under an effor of the hand. a pressure of 2000 kilograms. The hepatic pedicle was superficially fibrous. The crushing was carried out with great prudence, and succeeded so well that two ligatures of catgut en chaine sufficed for Radica. The pedicle, which was very short. was cut between this first ligature and Doodica, and three- voluminous arteries were immediately seized with pincers and tied up. The hemostasis, on the side of Doodica, was completed by two ligatures en chaine. The back part of the peritoneum, that on the side of
Doodica, and then the skin, were severed with a few cuts of the scissors, Doodica, liberated from her sister, was carried to a neighboring table, a compress was placed on the wound, and the skin temporarily fastened over it with pincers. 'The operation was then terminated on Radica, the hemostasis verifled, and the abdomdrain the wound.

The operation itself was cinematographed. This operation has only been carried out once before by Dr. Chapost-Prevost in Brazil. One of the patients died. For the first few days the condition of both Radica and Doodica steadily improved, but on Sunday morning Doodica died suddenly, after having shown symptoms of embolism. Dr. Doyen and the authorities at the Trousseau Hospital have had a dispute in the papers. Dr. Guinon contradicted the statement made by Dr. Doyen that the twins had been worried by medical students examining them, and Dr. Doyen said that when they arrived at his clinic they were found covered with vermin and affected with thrush.

\section{Gorrespondence.}

Papers Fraudulently Obtained from the Department of Medicine and Surgery of the University of Michigan.

Axy Arbor, Mich., Feb. 26, 1902.

To the Editor:-The medical profession may possibly be interested in a brief statement of the following facts: Some years ago I received from a physician at a small town in northern Michigan a letter stating that Dr. Emma W. Mooers, who graduated in the Department of Medicine and Surgery of the University of Michigan in 1884, was practicing medicine in an irregular way in his place. I knew that $\mathrm{Dr}$. Mooer's was pathologist to the McIean Hospital at Waverly, Mass., and 1 wrote my medical friend that the person impersonating Dr. Mooers was a fraud. Papers were issued for her arrest, but before they were served she left the town. Soon after this, the fraudulent Dr. Mooers turned up in Chicago, and I made another attempt to secure her arrest, but again she evaded the officers of the law and for some years disappeared. I few months ago I learned that she had registered under the name of E. W. M. Cory before the State Board of Medical lixaminers in Colorado, and I requested Dr. Van Meter, secretary of their. board, to secure her arrest. [See Tine Journal, March 1, p. 590, Colorarlo News.] This was done. and the woman was tried, conricted and sentenced to the penitentiary for one year. The judge allowed her to go on parole instead of being sent to the penitentiary, but she is to report once a month, and if she leaves the state she becomes a fugitive convict.

Now, the paper that this woman had was a certificate signed by James H. Wade, secretary of the University of Michigan, stating that Emma W. Mooers had graduated in the Department of Medicine and Surgery of this University in 1884. The fraudulent woman had written to Mr. Wade that she was Emma W. Mooers, who graduated in 1884, and that her liploma had been destroyed by fire, and requested a certificate of graduation. The secretary looked over the list of graduates for that year, and, finding the name in this list, sent the certificate. I report this case because, in the first place, the impersonator has given great annoyance to the real Dr. Mooers, whose work has been of the highest character and whose conduct has always been strictly professional; and in the second place, it shows that university authorities, at least the authorities of this university, have in the past not exercised sufficient care in issuing certificates of graduation to those who have claimed that their diplomas have been destroyed.

Thanks are due to Dr. Van Meter, of the Colorado State Board of Medical Examiners, and to the assisting prosecuting attorney, Mr. Smith, of Denver, for the energy with which they pushed this case. It is possible that the University of Michigan, through its secretary, has issued certificates of graduation to others who do not deserve them, and I desire to call the attention of state boards of medical examiners to this possibility. It is also possible that other institutions have been imposed upon in like manner. Dr. Van Meter, in a letter to me concerning this matter, suggests that it might be desirable for each diploma to contain some description of the person to whom it is granted in order that such a person may be recognized. This is a matter. worthy of consideration. 
The second instance of obtaining fraudulent papers is quite as serious as the one referred to above, although quite different in character. Iast year the medical faculty of this univerversity expelled one of its students on account of gross immorality. He was furnished with a statement of his class standing, and across this statement in red ink was written "Expelled for gross immorality." This statement was signed by the dean and secretary. Some time later, I learned that this man had entered Rush Medical College. I therefore wrote to Dr. Dodson, dean of that school, asking why he had accepted the man. Dr. Dodson sent me the credentials which the young man had presented him. The young man had had printed a duplicate of the statement given him; had made his class standings all right; and had omitted the statement of the cause of his expulsion. More than this, he had forged the names of the dean and secretary of this school. When these facts were made known to Rush Medical faculty, the young man was immediately expelled from that school. Such an experience as this indicates that the officials of medical schools should exercise more care in accepting credentials from other schools. Respectfully yours, Victor C. VaughaN, M.D.

\section{County Society Membership.}

KingSTON-ON-HUDSON, Feb. 24, 1902.

To the Editor:-Tire Jourval of Feb. 22-page 525-contains a letter from Dr. William P. Munn, of Denver, concerning the reorganization of state medical societies. The point to which he takes exception is that in all cases membership in the county society shall constitute membership in the state society, and that membership in the lower body shall be necessary for membership in the higher. His objection is that this is unfair to certain honorable members of the profession, who are al. ready members of the state societies, but who do not care to work in county organizations. (He also refers to the judicial side of the question, upon which $I$ have no opinion to offer.) From my own experience with physicians it seems incredible that any honorable physician could wish to do other than work in his own county society and do all in his power to make it an organization that would merit the respect of the community, so that when its members came together and expressed themselves in matters pertaining to the public good their opinion would be respected.

It certainly would seem to be just to both old and new members that there should be a common standard for all alike; that the opinion of the majority of the physicians of one's own community, who know him best, rather than that of the members of the state society, should determine one's membership. This seems so just and reasonable that $I$ fail to see any necessity for special exemptions or any good to come from them. When the medical profession of the United States becomes reorganized upon this basis it is reasonable to expect two results: 1. It will wield a power in the national, state, and local affairs worthy of the dignity of the profession; for physicians will have learned how to work effectively together. 2. No physician will be practicing medicine very near, if not over, the border line of quackery, in his own community while still preserving some remnants of professional respectability for himself by membership in a state society, and the American Medical Association. MaIrY Gage-DaY, M.D.

\section{Reflex in Irritable Urethra.}

BAGLey, Iowa, March 4, 1902.

To the Editor:-An aid in the diagnosis of irritable or irritated urethral mucous membrane and in the so-called uricacidemics, especially in those where there is great benefit derived from a few passages of the cold steel sound, is what may be called the "umbilico-urethral reflex." The elicitation of this is an easy matter in lean individuals, but in fat persons, diffieult, yet practicable.

The manner of performance is a movement from above down ward of the nail of the forefinger over the exact center of the umbilicus-"a seratching"-and done not quickly or lightly. This causes the above characterized patients to complain of a sharp, shooting, cutting pain, sometimes of momentary per- sistence followed by a desire to urinate-from the neck of the bladder to the meatus urethrse.

I will not attempt to explain the observation, but believe it due to the complex innervation of the fetal remnants of the illantois-the urachus-in the adult, and the genito-urinary tract. I have scen no mention of this in literature to which $I$ have access, but if otherwise I would like to know. Yours sincerely, JAs. H, Morroway, JR.

\section{New Instrument.}

\section{STERILE SOAP MACHINE. J. H. FIRESTONE, M.D. FREEPORT, ILL.}

The accompanying cut shows something new in the line of a foot-power sterile soap machine for use in operating rooms.

It consists of a cylinder and plunger, operated by foot power, applied to a ratchet wheel acting upon the arm of the piston by a double-thread screw, which forces the plunger into the cylinder. There are two blank screw eaps that go with each cylinder. The plunger, cylinder and contents are sterilized beiore using.

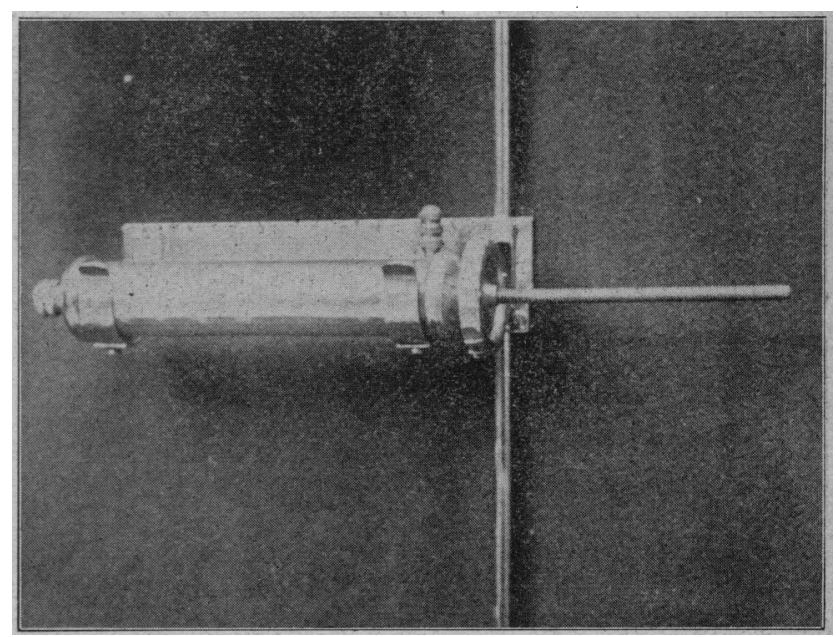

The machine is taken from the bracket and the plunger removed from the cylinder; then the cylinder is filled with green soap and the blank caps are screwed on either end. The filled cylinder and plunger are then sterilized. After sterilizing the blank caps are taken off, the plunger is adjusted and the machine is placed in the bracket ready to operate.

The machine is made in three sizes, each containing 1/2, 1 or 2 pounds of green soap.

\section{State Boards of Registration.}

Utah State Examination.-The Board of Medical Examiners of the State of Utall held its regular quarterly examination at Salt Lake City, January 6 and 7 . The number of subjects examined in were 10; total number of questions, 70 ; percentage required to pass, 75 . The number of applicants were 6 , of whom 5 passed.

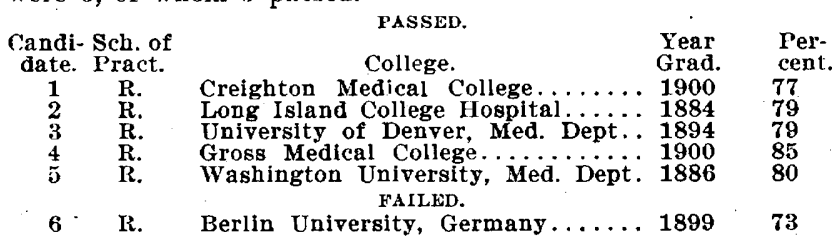

Can Not Practice in District of Washington Pending Examination.- In the case of a physician of Alexandria, Va., a graduate of the Columbian University School of Medicine, who requests the privilege of following his profession in the District until an opportunity is given him to take the examination prescribed for practicing physicians, Dr. William C. Woodward, the health ofticer, has submitted a report in which 